\title{
Climatology of GPS ionospheric scintillations over high and mid-latitude European regions
}

\author{
L. Spogli ${ }^{1}$, L. Alfonsi ${ }^{1}$, G. De Franceschi ${ }^{1}$, V. Romano ${ }^{1,2}$, M. H. O. Aquino ${ }^{2}$, and A. Dodson ${ }^{2}$ \\ ${ }^{1}$ Istituto Nazionale di Geofisica e Vulcanologia (INGV), Rome, Italy \\ ${ }^{2}$ Institute of Engineering Surveying and Space Geodesy (IESSG), Nottingham, UK
}

Received: 14 May 2009 - Revised: 3 August 2009 - Accepted: 20 August 2009 - Published: 1 September 2009

\begin{abstract}
We analyze data of ionospheric scintillation in the geographic latitudinal range $44^{\circ}-88^{\circ} \mathrm{N}$ during the period of October, November and December 2003 as a first step to develop a "scintillation climatology" over Northern Europe. The behavior of the scintillation occurrence as a function of the magnetic local time and of the corrected magnetic latitude is investigated to characterize the external conditions leading to scintillation scenarios. The results shown herein, obtained merging observations from four GISTM (GPS Ionospheric Scintillation and TEC Monitor), highlight also the possibility to investigate the dynamics of irregularities causing scintillation by combining the information coming from a wide range of latitudes. Our findings associate the occurrences of the ionospheric irregularities with the expected position of the auroral oval and ionospheric troughs and show similarities with the distribution in magnetic local time of the polar cap patches. The results show also the effect of ionospheric disturbances on the phase and the amplitude of the GPS signals, evidencing the different contributions of the auroral and the cusp/cap ionosphere.
\end{abstract}

Keywords. Ionosphere (Ionospheric irregularities) - Magnetospheric physics (Polar cap phenomena) - Radio science (Space and satellite communication)

\section{Introduction}

Under perturbed conditions caused by intense solar windmagnetosphere coupling, the ionosphere may become highly turbulent and irregularities, typically enhancements or depletions of the electron density embedded in the ambient ionosphere, can form. At high latitude irregularities have scale sizes ranging from hundreds of kilometers down to a few

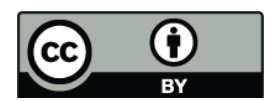

Correspondence to: L. Spogli

(luca.spogli@ingv.it) centimeters and the structures are highly dynamic. Such irregularities cause diffraction effects on the satellites signals passing through them, abruptly corrupting the performance of the positioning systems (Committee on the Societal and Economic Impacts of Severe Space Weather Events, 2008).

The fluctuations in the carrier frequency of the radio waves received at the ground, commonly called ionospheric amplitude and phase scintillations, can be analyzed to investigate the physical processes causing them and, conversely, to understand how these processes affect the operational capabilities of GNSS (Global Navigation Satellite System) receivers. The Istituto Nazionale di Geofisica e Vulcanologia (INGV) and the Institute of Engineering Surveying and Space Geodesy (IESSG) of the University of Nottingham manage the same kind of GISTM (GPS Ionospheric Scintillation and TEC Monitor) receivers over the European middle and high latitude regions. The activity started in 2001 and it is still in progress. The scintillation data used in this paper originates from four GISTM receivers, which consist of NovAtel OEM4 dual-frequency receivers with special firmware specifically able to compute in near real time the amplitude and the phase scintillation from the GPS L1 frequency signals, and the ionospheric TEC (Total Electron Content) from the GPS L1 and L2 carrier phase signals. The amplitude scintillation is monitored by computing the $\mathrm{S}_{4}$ index, which is the standard deviation of the received power normalized by its mean value. Phase scintillation computation is accomplished by monitoring the $\sigma_{\phi}$ index, the standard deviation of the detrended carrier phase, computed over different time intervals: 1, 3, 10, 30 and $60 \mathrm{~s}$. These indices are both based on $50 \mathrm{~Hz}$ measurements at L1 frequency (Van Dierendonck et al., 1993). The IESSG receivers are located at Hammerfest (HAM), Brønnøysund (BRO) and Nottingham (NOT), whereas INGV's is located at Ny-Ålesund (NYA), as shown in Fig. 1.

In Table 1 the geographic and corrected geomagnetic coordinates of the stations are shown, together with the range of

Published by Copernicus Publications on behalf of the European Geosciences Union. 
Table 1. Geographic and corrected geomagnetic coordinates together with the magnetic latitude range of the field of view of the GISTM receiver sites at $350 \mathrm{~km}$.

\begin{tabular}{cccccc}
\hline Station ID & $\begin{array}{c}\text { Geographic } \\
\text { latitude }\end{array}$ & $\begin{array}{c}\text { Geographic } \\
\text { longitude }\end{array}$ & $\begin{array}{c}\text { Corrected geomagnetic } \\
\text { latitude }\end{array}$ & $\begin{array}{c}\text { Corrected geomagnetic } \\
\text { longitude }\end{array}$ & $\begin{array}{c}\text { Corrected geomagnetic } \\
\text { latitude range }\end{array}$ \\
\hline NYA & $78.9^{\circ} \mathrm{N}$ & $11.9^{\circ} \mathrm{E}$ & $76.0^{\circ} \mathrm{N}$ & $112.3^{\circ} \mathrm{E}$ & $68^{\circ}-84^{\circ} \mathrm{N}$ \\
HAM & $70.7^{\circ} \mathrm{N}$ & $23.7^{\circ} \mathrm{E}$ & $67.2^{\circ} \mathrm{N}$ & $108.0^{\circ} \mathrm{E}$ & $58^{\circ}-76^{\circ} \mathrm{N}$ \\
BRO & $65.5^{\circ} \mathrm{N}$ & $12.2^{\circ} \mathrm{E}$ & $62.6^{\circ} \mathrm{N}$ & $95.1^{\circ} \mathrm{E}$ & $54^{\circ}-72^{\circ} \mathrm{N}$ \\
NOT & $52.9^{\circ} \mathrm{N}$ & $1.2^{\circ} \mathrm{W}$ & $54.8^{\circ} \mathrm{N}$ & $87.1^{\circ} \mathrm{E}$ & $40^{\circ}-58^{\circ} \mathrm{N}$ \\
\hline
\end{tabular}

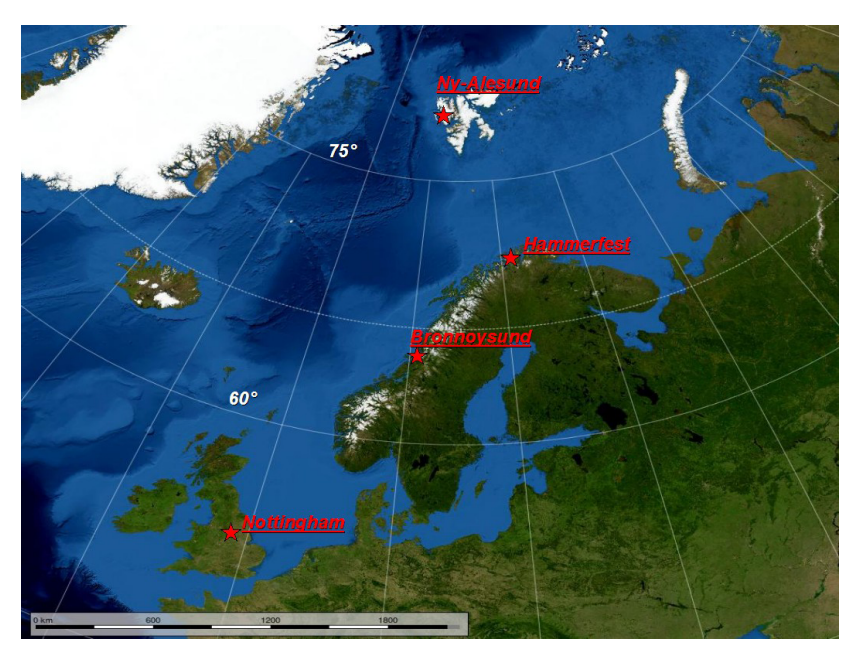

Fig. 1. Location of the sites.

the field of view of every station at the sub-ionospheric height of $350 \mathrm{~km}$ and with an elevation threshold of 15 degrees (see Sect. 3). The HAM and BRO field of view covers auroral latitudes for most MLT's, the NOT one covers mid-latitudes, while NYA is located close to the cusp around magnetic noon and under the polar cap on the nightside.

The paper focus on the construction and discussion of "scintillations maps" for both the scintillation indices over the whole period under investigation, also considering the diverse contribution of disturbed and quiet days, defined according to $K_{p}$, the geomagnetic planetary index (see Sect. 2). The scintillation maps provide information on the cusp/cap effect and on the expansion of the auroral oval and trough (see e.g. De Franceschi et al., 2008). The high latitude trough is a depression in ionization (principally due to a depletion of $\mathrm{O}^{+}$), occurring mainly in the night-time sector, and most evident in the upper F-region. The latitudinal boundaries of the trough may be sharp, especially the poleward boundary with the auroral oval (see e.g. Werner and Prolss, 1997). Inside the polar cap phase scintillations are associated with patches, discrete electron density enhancements occurring in the Fregion, with horizontal scales of $100-1000 \mathrm{~km}$ and convecting across the cap in a generally anti-sunward direction (see e.g. Buchau et al., 1983). The poleward and equatorward boundaries of the auroral oval and the walls of the ionospheric trough are privileged sites to host irregularities associated with scintillation phenomena at mid and high latitudes.

The paper is organized as follows: Sect. 2 describes the geomagnetic characterization of the selected period and illustrates the method adopted to define the quiet and disturbed behavior of each day; Sect. 3 introduces the data analyzed in the study and Sect. 4 shows the method of producing the "scintillations maps", together with some statistical considerations, while the results of the investigation are given in Sect. 5. Final remarks and conclusions are in Sect. 6.

\section{Geomagnetic characterization}

The period under investigation is characterized by two intense magnetic storms and important scintillation events occurred on 30-31 October and on 20-21 November 2003, as described in the recent literature (see, e.g., Mitchell et al., 2005; Foster and Rideout, 2005; De Franceschi et al., 2008). Figure 2 shows the variation of the $K_{p}$ index during October, November and December 2003, provided by the World Data Center for Geomagnetism of Kyoto. $K_{p}$ maximizes around $30-31$ October and 20-21 November and is used in this paper to define the geomagnetic behavior of a particular day, which is assumed to be quiet if every $K_{p}$ value is strictly less than 5 and if $50 \%$ of values in that day is less than or equal to 4. According to this assumption, about half of the days in each month is found to be disturbed, as shown in Fig. 3. Despite the inclusion of the extreme perturbed cases due to solar storms, several aspects of a possible scintillation scenario over Northern Europe can be highlighted for climatologic purpose, as will be shown in Sect. 5 .

\section{Data}

Scintillation indices computed over $60 \mathrm{~s}$ are analyzed during the three months of the exercise (October, November and December 2003): the total number of data points is of the order of 1 million per station. In order to reduce the impact of 

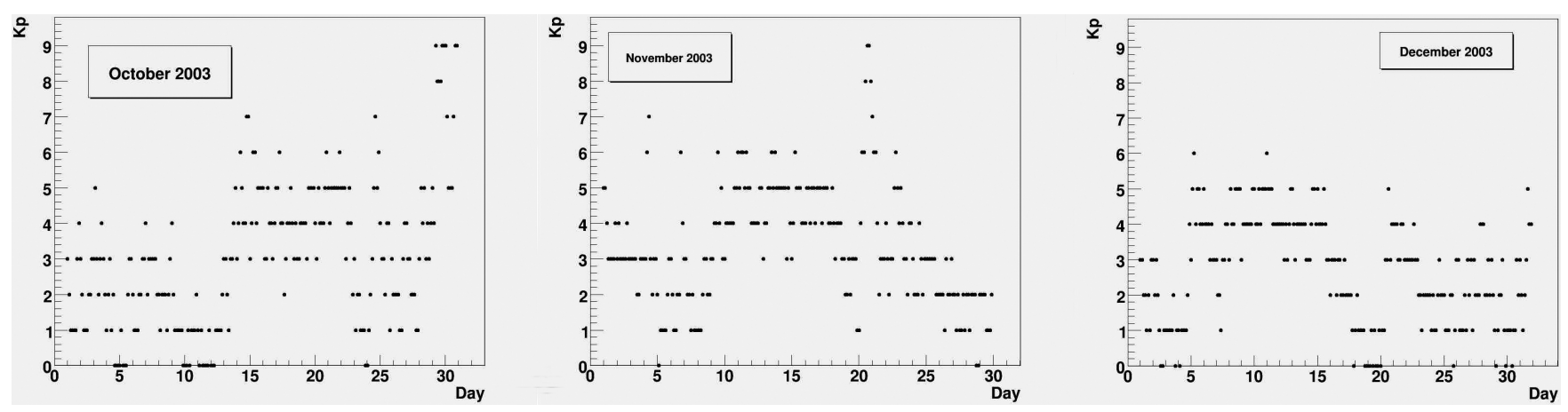

Fig. 2. Variation of $K_{p}$ index during October, November and December 2003 (World Data Center for Geomagnetism of Kyoto).

\begin{tabular}{|c|c|}
\hline Date & Quiet/Disturbed \\
\hline $01 / 10 / 2003$ & quiet \\
\hline $02 / 10 / 2003$ & quiet \\
\hline $03 / 10 / 2003$ & disturbed \\
\hline $04 / 10 / 2003$ & quiet \\
\hline $05 / 10 / 2003$ & quiet \\
\hline $06 / 10 / 2003$ & quiet \\
\hline $07 / 10 / 2003$ & quiet \\
\hline $08 / 10 / 2003$ & quiet \\
\hline $09 / 10 / 2003$ & quiet \\
\hline $10 / 10 / 2003$ & quiet \\
\hline $11 / 10 / 2003$ & quiet \\
\hline $12 / 10 / 2003$ & quiet \\
\hline $13 / 10 / 2003$ & disturbed \\
\hline $14 / 10 / 2003$ & disturbed \\
\hline $15 / 10 / 2003$ & disturbed \\
\hline $16 / 10 / 2003$ & disturbed \\
\hline $17 / 10 / 2003$ & disturbed \\
\hline $18 / 10 / 2003$ & disturbed \\
\hline $19 / 10 / 2003$ & disturbed \\
\hline $20 / 10 / 2003$ & disturbed \\
\hline $21 / 10 / 2003$ & disturbed \\
\hline $22 / 10 / 2003$ & disturbed \\
\hline $23 / 10 / 2003$ & quiet \\
\hline $24 / 10 / 2003$ & disturbed \\
\hline $25 / 10 / 2003$ & quiet \\
\hline $26 / 10 / 2003$ & quiet \\
\hline $27 / 10 / 2003$ & quiet \\
\hline $28 / 10 / 2003$ & disturbed \\
\hline $29 / 10 / 2003$ & disturbed \\
\hline $30 / 10 / 2003$ & disturbed \\
\hline $31 / 10 / 2003$ & disturbed \\
\hline
\end{tabular}

\begin{tabular}{|c|c|}
\hline Date & Quiet/Disturbed \\
\hline $01 / 11 / 2003$ & disturbed \\
\hline $02 / 11 / 2003$ & quiet \\
\hline $03 / 11 / 2003$ & disturbed \\
\hline $04 / 11 / 2003$ & disturbed \\
\hline $05 / 11 / 2003$ & quiet \\
\hline $06 / 11 / 2003$ & disturbed \\
\hline $07 / 11 / 2003$ & quiet \\
\hline $08 / 11 / 2003$ & quiet \\
\hline $09 / 11 / 2003$ & disturbed \\
\hline $10 / 11 / 2003$ & disturbed \\
\hline $11 / 11 / 2003$ & disturbed \\
\hline $12 / 11 / 2003$ & disturbed \\
\hline $13 / 11 / 2003$ & disturbed \\
\hline $14 / 11 / 2003$ & disturbed \\
\hline $15 / 11 / 2003$ & disturbed \\
\hline $16 / 11 / 2003$ & disturbed \\
\hline $17 / 11 / 2003$ & disturbed \\
\hline $18 / 11 / 2003$ & disturbed \\
\hline $19 / 11 / 2003$ & quiet \\
\hline $20 / 11 / 2003$ & disturbed \\
\hline $21 / 11 / 2003$ & disturbed \\
\hline $22 / 11 / 2003$ & disturbed \\
\hline $23 / 11 / 2003$ & disturbed \\
\hline $24 / 11 / 2003$ & quiet \\
\hline $25 / 11 / 2003$ & quiet \\
\hline $26 / 11 / 2003$ & quiet \\
\hline $27 / 11 / 2003$ & quiet \\
\hline $28 / 11 / 2003$ & quiet \\
\hline $29 / 11 / 2003$ & quiet \\
\hline $30 / 11 / 2003$ & quiet \\
\hline
\end{tabular}

\begin{tabular}{|c|c|}
\hline Date & Quiet/Disturbed \\
\hline $01 / 12 / 2003$ & quiet \\
\hline $02 / 12 / 2003$ & quiet \\
\hline $03 / 12 / 2003$ & quiet \\
\hline $04 / 12 / 2003$ & quiet \\
\hline $05 / 12 / 2003$ & disturbed \\
\hline $06 / 12 / 2003$ & disturbed \\
\hline $07 / 12 / 2003$ & quiet \\
\hline $08 / 12 / 2003$ & disturbed \\
\hline $09 / 12 / 2003$ & disturbed \\
\hline $10 / 12 / 2003$ & disturbed \\
\hline $11 / 12 / 2003$ & disturbed \\
\hline $12 / 12 / 2003$ & disturbed \\
\hline $13 / 12 / 2003$ & disturbed \\
\hline $14 / 12 / 2003$ & disturbed \\
\hline $15 / 12 / 2003$ & disturbed \\
\hline $16 / 12 / 2003$ & quiet \\
\hline $17 / 12 / 2003$ & quiet \\
\hline $18 / 12 / 2003$ & quiet \\
\hline $19 / 12 / 2003$ & quiet \\
\hline $20 / 12 / 2003$ & quiet \\
\hline $21 / 12 / 2003$ & disturbed \\
\hline $22 / 12 / 2003$ & quiet \\
\hline $23 / 12 / 2003$ & quiet \\
\hline $24 / 12 / 2003$ & quiet \\
\hline $25 / 12 / 2003$ & quiet \\
\hline $26 / 12 / 2003$ & quiet \\
\hline $27 / 12 / 2003$ & quiet \\
\hline $28 / 12 / 2003$ & quiet \\
\hline $29 / 12 / 2003$ & quiet \\
\hline $30 / 12 / 2003$ & quiet \\
\hline $31 / 12 / 2003$ & quiet \\
\hline
\end{tabular}

Fig. 3. List of days and their geomagnetic characterization.

non-scintillation related tracking errors (such as multipath) only indices computed from observations at elevation angles greater than $15^{\circ}$ are considered. Scintillation indices are projected to the vertical, in order to account for varying geometrical effects on the measurements made at different elevation angles, as in the following formulae:

$\sigma_{\varphi}\left(\alpha_{\mathrm{elev}}=90^{\circ}\right)=\sigma_{\varphi}\left(\alpha_{\mathrm{elev}}\right) \sin ^{a}\left(\alpha_{\mathrm{elev}}\right)$

$S_{4}\left(\alpha_{\text {elev }}=90^{\circ}\right)=S_{4}\left(\alpha_{\text {elev }}\right) \sin ^{b}\left(\alpha_{\text {elev }}\right)$,
Where $\alpha_{\text {elev }}$ is the elevation angle, $\sigma_{\phi}\left(\alpha_{\text {elev }}\right)$ and $S_{4}\left(\alpha_{\text {elev }}\right)$ are the indices directly measured by the receivers at a given elevation angle, along the path between satellite and receiver. According to formula (19) of Rino (1979), which describes the signal phase variance as a function of the zenith angle, the exponent of the phase, $a$, is assumed to be 0.5 , while $b$ depends on the spectral index of the phase scintillation spectrum, $p$, and on the irregularities anisotropy. The theory described by Rino (1979) and the data-driven model in Wheelon (2001) suggest different dependencies on $p$. For the sake of completeness, we applied different choices of $p$ to 
Table 2. Available days of data of each receiver for each months: the corresponding percentage is in open brackets.

\begin{tabular}{lcccc}
\hline & NYA & HAM & BRO & NOT \\
\hline October & $30(97.8 \%)$ & $30(97.8 \%)$ & $30(97.8 \%)$ & $29(93.5 \%)$ \\
November & $30(100 \%)$ & $30(100 \%)$ & $30(100 \%)$ & $30(100 \%)$ \\
December & $29(93.5 \%)$ & $19(61.3 \%)$ & $20(64.5 \%)$ & $29(93.5 \%)$ \\
\hline
\end{tabular}

our analysis, without finding any qualitative distinction in the behavior of the amplitude scintillation maps. With regards to this consideration and according to Wernik et al. (2003), we show only maps for $p=2.6$, corresponding to $b=0.9$. For the remainder of this paper the indices refer to their vertically projected values. Data are available for the most part of the period, even if there are some significant data gaps, mainly found in December and for the auroral stations. Available days of data of each receiver in each months, together with the corresponding percentage, are in Table 2.

\section{Method}

Merging the information from the four stations, we construct maps of percentage of occurrence of the scintillation indices in Altitude Adjusted Corrected Geomagnetic Coordinates (Baker and Wing, 1989): Magnetic Latitude $\left(M_{\text {lat }}\right)$ vs. Magnetic Local Time (MLT). The percentage of occurrence is evaluated for each bin of $3 \mathrm{~h} \mathrm{MLT} \times 2^{\circ} M_{\text {lat }}$, i.e. a good compromise between the large statistics required in each bin and a meaningful fragmentation of the map, as:

$\frac{N\left(S_{4} \operatorname{or} \sigma_{\varphi}>\text { threshold }\right)}{N_{\text {tot }}}$,

where $N\left(S_{4}\right.$ or $\sigma_{\phi}>$ threshold $)$ is the number of data points corresponding to a scintillation index above a given threshold and $N_{\text {tot }}$ is the total number of data points in the bin. The selected thresholds are 0.25 radians for $\sigma_{\phi}$ and 0.25 for $S_{4}$. These choices satisfy the need of a meaningful sample and the necessity of distinguishing moderate/strong scintillations. To remove the contribution of bins with poor statistics we assume that the selected accuracy, defined as (Taylor, 1997):

$R_{=} 100 \times \frac{\sigma\left(N_{\mathrm{tot}}\right)}{N_{\mathrm{tot}}}=\frac{100}{\sqrt{N_{\mathrm{tot}}}}$,

has to be lower than $2.5 \%$. In formula (2), $\sigma\left(N_{\text {tot }}\right)=\left(N_{\text {tot }}\right)^{1 / 2}$ is the standard deviation of the number of data points in each bin. The threshold value of $2.5 \%$ is a good compromise between the necessity to include every meaningful bin in the map and to avoid possible overestimations of the accuracy due to scarce statistics. Typically, bins not satisfying the condition on accuracy are in the border of the field of view of the stations. We superimposed to the scintillation occurrence maps the position of the Feldstein auroral oval (Feldstein, 1963; Holzworth and Meng, 1975) for two different level of magnetic activity (IQ), to investigate the ionospheric regions more affected by scintillation. We choose $\mathrm{IQ}=3$ as representative of the quiet ionosphere and $\mathrm{IQ}=6$ for the disturbed ionosphere, being aware that very unsettled conditions of the ionosphere generally are not realistically described by the model. Hereafter we refers to this two ovals as quiet oval $(\mathrm{IQ}=3)$ and disturbed oval $(\mathrm{IQ}=6)$.

\section{Observations and discussion}

Figure 4 shows the maps of percentage of occurrence of the whole period under consideration for both the scintillation indices with the Feldstein disturbed (red) and quiet (grey) ovals overlapped: left plot is for $\sigma_{\phi}$, while right is for $S_{4}$.

At a first glance Fig. 4 highlights that polar areas are much more sensitive to signal phase scintillation than amplitude scintillation $(\sim 2.8 \%$ of peak occurrence for the phase, while $\sim 0.16 \%$ for the amplitude), confirming what has already been found by other authors (Meggs et al., 2008; Humpreys et al., 2005; Rodrigues et al., 2004; Doherty et al., 2000). The general behavior of the two indices is significantly different: the $S_{4}$ map seems to be confined in well defined regions, while the $\sigma_{\phi}$ map shows a strong characterization both in $M_{\text {lat }}$ and MLT. The different distributions could be explained by looking at the scale of the irregularities which depends also on the anisotropy due to the irregularities field alignment. As described in Wernik et al. (1990), smaller irregularities (typically causing scintillation on L-band) are more anisotropic than large ones, and irregularities of different shapes can be found at different geomagnetic latitudes. The present investigation is not focused on the role of the anisotropy in the scintillation occurrence, because this topic is worthy of a dedicated paper, currently in preparation.

A detailed description of the two scintillation indices occurrence is reported in the following subsections.

\subsection{Phase scintillation}

The phase scintillations on GNSS signals are likely caused by ionospheric irregularities of scale size of hundreds of meters to few kilometers (see e.g. Hunsucker and Hargreaves, 2003). Figure 5 shows the maps of $\sigma_{\phi}$ percentage of occurrence including data from the four stations: on the left the quiet days, on the right the disturbed days. In both the cases two MLT regions are in evidence: one around magnetic midnight and another one around magnetic noon. The main difference arising in the comparison is that, in the case of disturbed days, the occurrence is generally larger and the scintillation regions shift to lower magnetic latitudes. The latter effect is due the displacement of the auroral oval under disturbed conditions, as shown by the oval curves. This was 

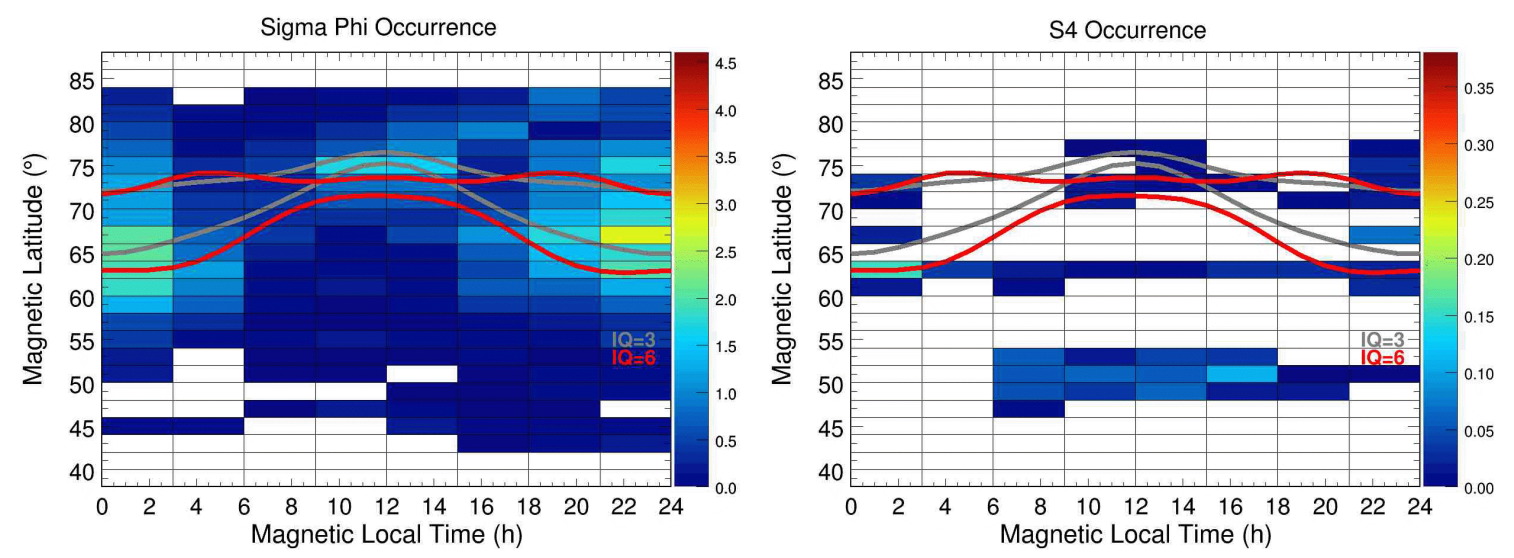

Fig. 4. Maps of $\sigma_{\phi}$ percentage of occurrence (left). Maps of $S_{4}$ percentage of occurrence (right). Note that the two color scales are different. Maps are for all stations and whole period. In grey the Feldstein oval for $\mathrm{IQ}=3$, while in red the one for $\mathrm{IQ}=6$.
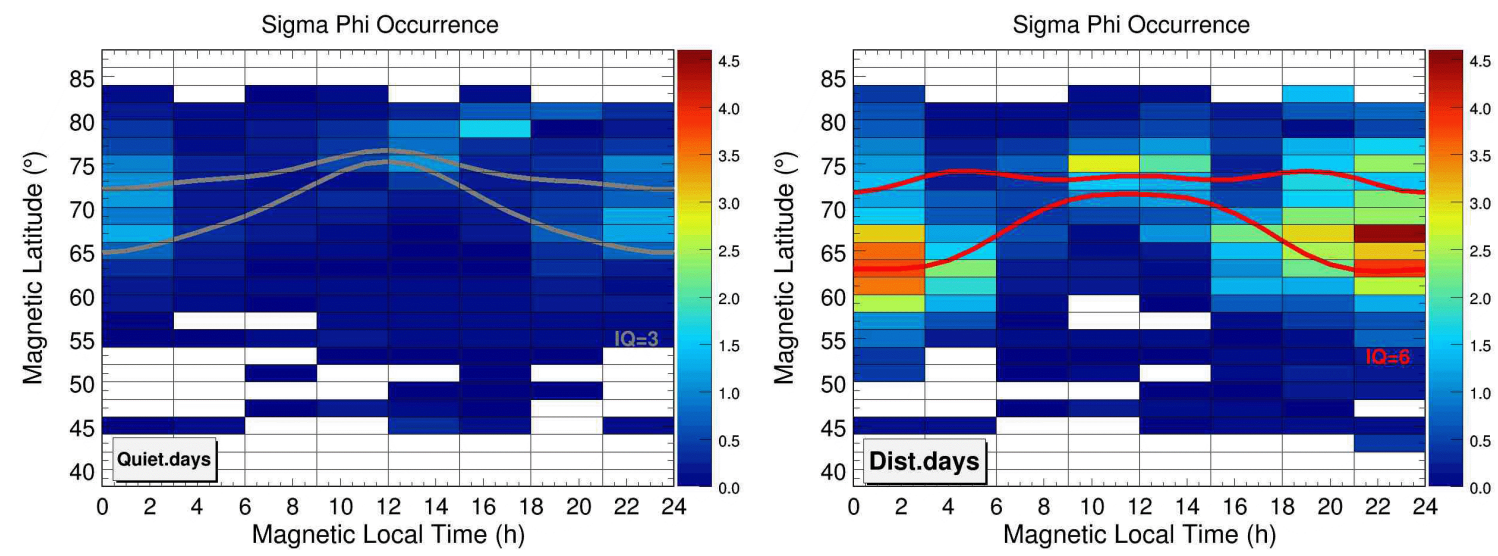

Fig. 5. Maps of $\sigma_{\phi}$ percentage of occurrence merging data from all stations: left is for the quiet days with the IQ=3 oval in grey, while right is for disturbed days with the $\mathrm{IQ}=6$ oval in red.

also found by Rodrigues et al. (2004) when analyzing data from the same region, including measurements recorded at stations HAM, BRO and NOT with the same receivers.

The MLT characterization of Fig. 5 can be explained looking at the position of the oval boundaries. In fact, the scintillation occurrence peaks at midnight and noon around the poleward and equatorward boundaries of the oval (both for quiet and disturbed ovals). Moreover the scintillation occurrence shows asymmetries probably associated to the trough minimum position i.e. the position of the depression zones in the electron density (Werner and Prolss, 1997). In fact Werner and Prolss (1997) found that troughs during noontime are located at high latitudes, during the afternoon they migrate toward lower latitudes, reaching the minimum early in the morning and showing an asymmetry of the trough position around noon. This explanation is confirmed by the correspondence with the reconstruction of the equatorward and poleward walls of the troughs during 2003 by Voiculescu et al. (2006). In a recent paper Wielgosz and co-authors (2004) demonstrate that the TEC distribution follows the position of the troughs, indicating the presence of large gradients in the electron concentration. The phase scintillation occurrence appears mostly due to the electron density gradients and this would explain the statistical behavior shown in the $\sigma_{\phi}$ maps (Fig. 5): see e.g. MacDougall (1990).

We found also a slight occurrence enhancement at high latitude (above $\sim 78^{\circ}$ ), describing an asymmetry around magnetic midnight (Fig. 5). It seems to show that the distribution favors the pre-midnight sector, according to what also found by Rodrigues et al. (2004). According to Moen et al. (2007), a similar asymmetry is identified in the distribution of the polar cap patches observed over Ny-Ålesund by Meridian Scanning Photometer data from 1997 to 2005. This would confirm the crucial role of the polar cap patches in producing scintillation (De Franceschi et al., 2008).

Comparing the quiet/disturbed maps in Fig. 5, it is evident the displacement to lower latitudes (from around $70^{\circ}$ to $65^{\circ}$ ) of the scintillation occurrence in the post-midnight sector 

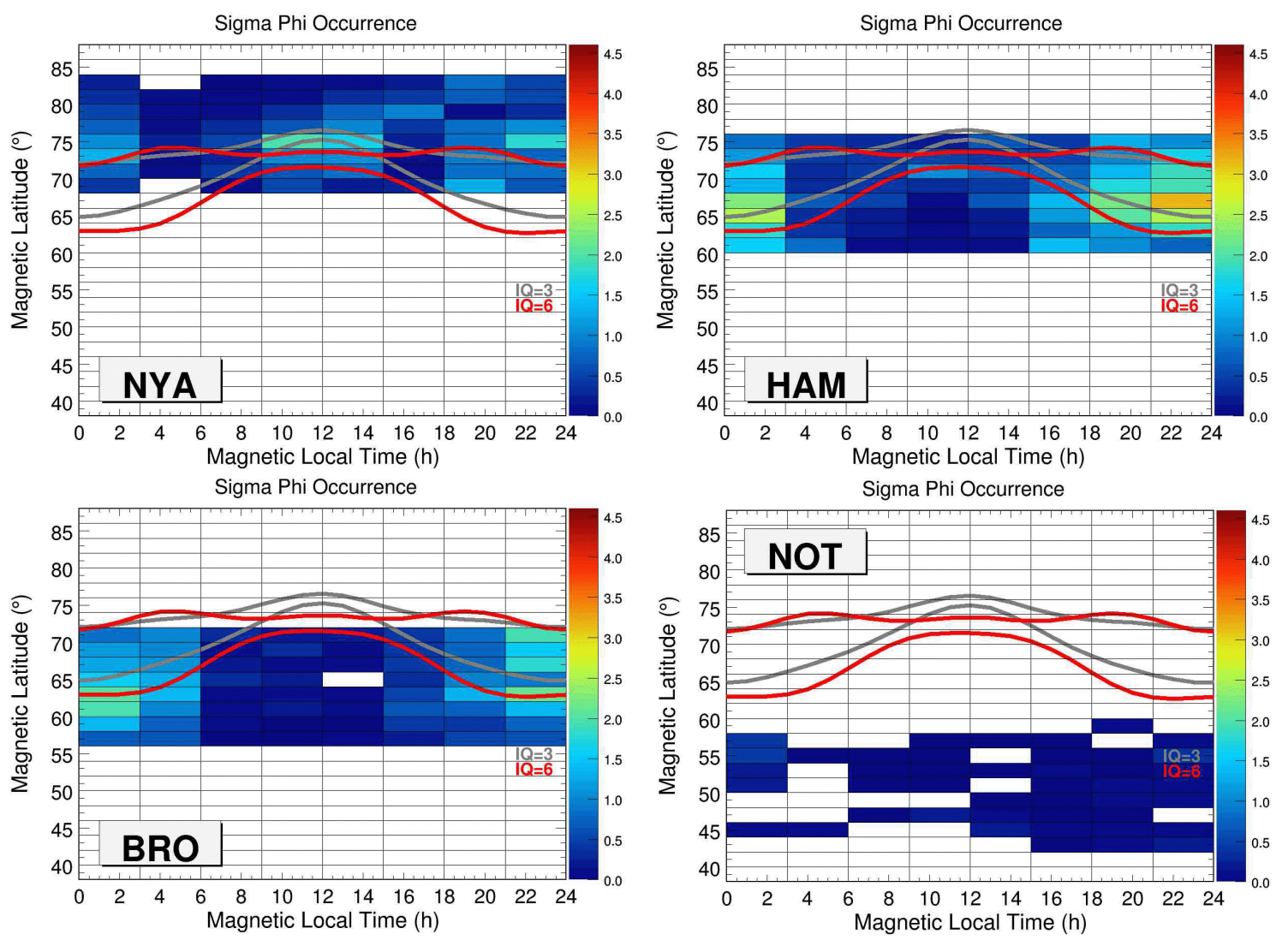

Fig. 6. Phase scintillation maps of all days and for each station separately. In grey the Feldstein oval for IQ=3, while in red the one for IQ=6.
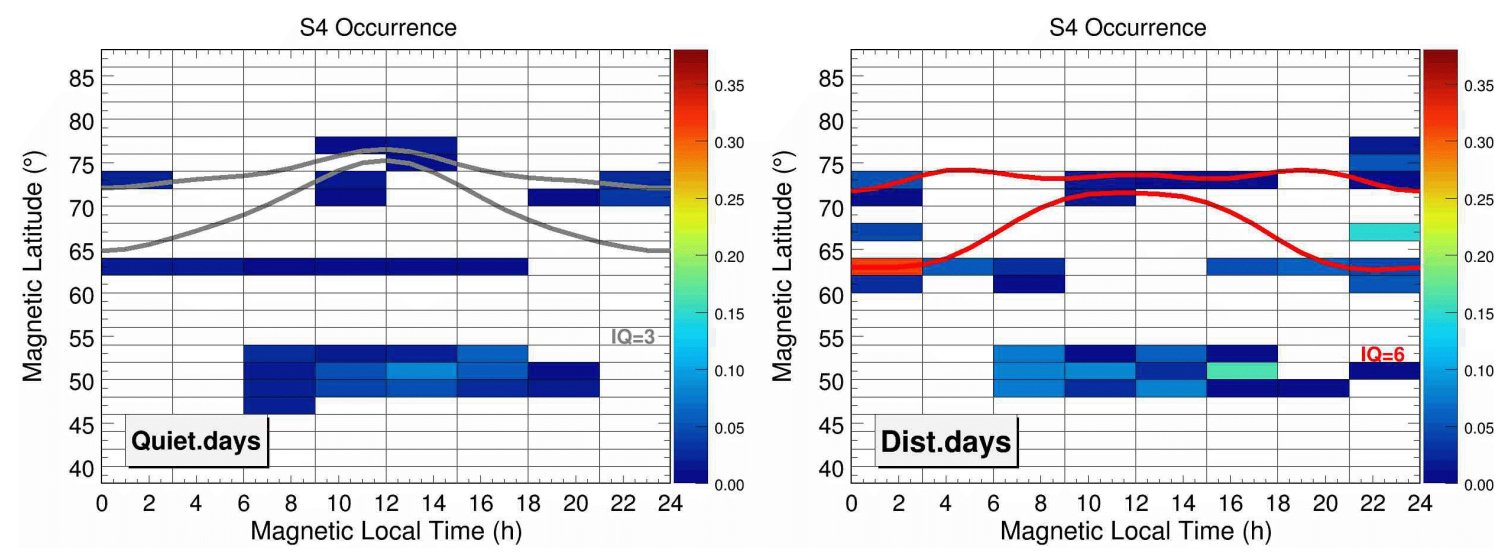

Fig. 7. Maps of $S_{4}$ percentage of occurrence merging data from all stations: left is for the quiet days with the IQ=3 oval in grey, while right is for disturbed days with the $\mathrm{IQ}=6$ oval in red.

under perturbed conditions. This result confirms the close relationship with auroral oval boundaries and with the trough position and it is in agreement with what found by Tsunoda (1988): the scintillation boundary follows closely the trough minimum under quiet conditions in the pre-midnight sector, but diverges during the post-midnight hours. The strong link between scintillation occurrence and patches distribution is evident in the quiet/disturbed days maps, with an increase of the asymmetry around midnight under perturbed conditions.

Figure 6 shows the individual contributions of each of the four stations, including all days (quiet and disturbed) in the period, evidencing the different fields of view of the stations and the different locations of the scintillation occurrence. The enhancement around noon is visible mainly in the NYA 

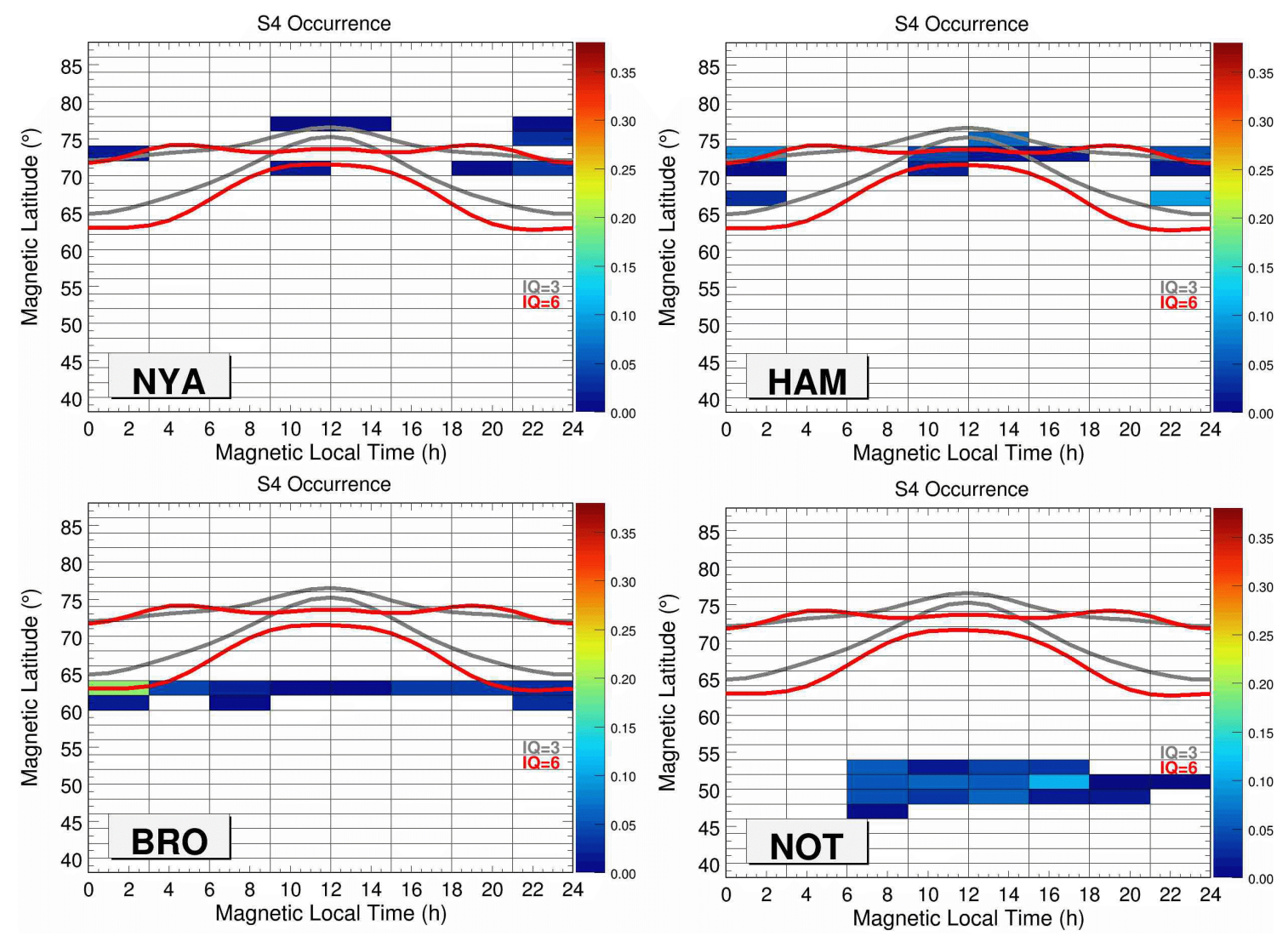

Fig. 8. Amplitude scintillation maps of all days and for stations NYA, HAM, BRO and NOT separately. In grey the Feldstein oval for IQ=3, while in red the one for $\mathrm{IQ}=6$.

map as an expected cusp effect due to the field of view of the station. To this enhancement contributes also the polar cap patches that form in the cusp and enters the polar cap in cusp inflow region (Moen et al., 2008). During midnight the enhancement and the asymmetry are evident also in the auroral stations (HAM and BRO), while NOT data contribute weakly to the midnight enhancement, maybe due to the equatorward boundary of the very disturbed oval. In fact, the very disturbed conditions induced by the storms in October and November 2003 are not well reproduced by the model. As an example, during 20 November, the equatorward boundary of the oval reached $\sim 50^{\circ}$ (see Fig. 2-26 of Goodman, 2005).

\subsection{Amplitude scintillation}

The amplitude scintillations on GNSS signals are caused by ionospheric irregularities of scale size smaller than the Fresnel radius, which is of the order of hundreds of meters for GPS signals (see e.g. Hunsucker and Hargreaves, 2003). Figure 7 shows the maps of $S_{4}$ percentage of occurrence together with the Feldstein quiet and disturbed ovals: on the left the quiet days, on the right the disturbed days. The contribution to the maps on the right of Fig. 4 comes mainly from the disturbed days (Fig. 7), except for the occurrence enhance- ment located below $55^{\circ}$ visible under both geomagnetic conditions. Both quiet and disturbed days plots of Fig. 7 show that the $S_{4}$ index enhances at noon and midnight in correspondence with the boundaries of the auroral oval. This highlights the regions of the oval boundaries as privileged sites to host irregularities causing amplitude scintillations. From the same picture (Fig. 7) the scintillation region below $55^{\circ}$ needs further investigations to be properly described.

Figure 8 shows the contribution of the four stations, separately. Concerning the location of the scintillation occurrence, enhancements at midnight and noon are present both in NYA and HAM (differently from the phase scintillation occurrence, Fig. 6), BRO receiver contributes to the scintillation occurrence in the region of the equatorward boundary of the auroral oval over all MLT's, while the scintillation area below $55^{\circ}$ derives from the field of view of the NOT receiver.

\section{Summary and conclusions}

In this analysis we constructed maps of occurrence of the phase and amplitude scintillation indices in Northern Europe as a function of magnetic latitude and magnetic local time, to 
characterize the scintillation behavior on GPS signals during October, November and December 2003.

Principal achievements of the work are:

1. Confirmation of higher sensitivity to phase scintillation with respect to amplitude scintillation of the polar ionosphere.

2. Observation of the displacement of scintillation regions towards lower latitudes during magnetically active periods (defined in Sect. 2).

3. Larger phase scintillation occurrence during the disturbed days than during quiet days, although of the same order of magnitude.

4. Characterization of the phase scintillation in terms of the auroral oval and ionospheric trough positions. The occurrence of phase scintillation follows the electron density gradients, often observed around the trough minimum position and in correspondence of the auroral oval boundaries.

5. Characterization of the asymmetry around midnight of the phase scintillation occurrence above $78^{\circ}$ in agreement with the polar cap patches distribution.

6. Observation of the displacement to lower latitudes of the phase scintillation occurrence in the post-midnight sector under perturbed conditions, confirming the close relation with the auroral oval and trough position.

7. The phase scintillation region around noon is mainly due to the cusp effect observed by the NYA receiver and to a lesser extent by the HAM receiver. The enhancement of the occurrence at midnight and its asymmetry towards afternoon is evident in HAM, BRO and NYA stations, with little contribution from the mid latitude station (NOT).

8. Amplitude scintillation occurrence during the disturbed days is one order of magnitude larger than during quiet days, differently from what found for phase scintillation.

9. Observation of the preponderance of the midnight effect during disturbed days for amplitude scintillation maps, while during quiet days the midnight and noon effects are of the same order of magnitude.

10. Observation of enhancements of occurrence in correspondence of the boundaries of the auroral oval at noon and midnight, confirming that the oval walls host irregularities causing amplitude scintillations.

11. Observation of enhancements at noon only in the individual amplitude scintillation occurrence maps of the higher latitude receivers (NYA, HAM), while the enhancements at midnight are present also in the BRO station. The NOT receiver contributes only below $55^{\circ}$.
This first step towards the development of scintillation climatology stimulates some questions that deserve a deeper investigation in future studies. Some of the open questions that must be addressed are:

- How the mid-latitude amplitude scintillation region can be explained?

- What is the role of the anisotropy of the irregularities in the scintillation production?

- What is the best indicator of the quiet/disturbed conditions for scintillation climatological purposes?

- In which way could spectral analysis improve the climatology?

- What are the other data sources that can be integrated to improve the interpretation?

This work aims to contribute to the development of nowcasting and forecasting tools for GPS ionospheric scintillation prediction.

Acknowledgements. The authors would like to thank Andrzej W. Wernik for his kind support and important comments. The authors also thank the Programma Nazionale di Ricerche in Antartide (PNRA), CNR (Consiglio Nazionale delle Ricerche), the World Data Center for Geomagnetism of Kyoto, the Engineering and Physical Sciences Research Council of the UK (EPSRC) and the Royal Society. The authors also thanks the National Space Science Data Center (NSSDC) for the software calculating the auroral oval position and the model authors: Holzworth and Meng.

Topical Editor M. Pinnock thanks two anonymous referees for their help in evaluating this paper.

\section{References}

Baker, K. B. and Wing, S.: A new magnetic coordinate system for conjugate studies at high latitudes, J. Geophys. Res., 94, 91399143, 1989.

Buchau, J., Reinisch, B. W., Weber, E. J., and Moore, J. G.: Structure and dynamics of the winter polar cap F-region, Radio Sci., 18, 995-1010,1983.

Committee on the Societal and Economic Impacts of Severe Space Weather Events: Severe Space Weather Events - Understanding Societal and Economic Impacts Workshop Report, ISBN: 0-30912770-X, 2008.

De Franceschi, G., Alfonsi, L., Romano, V., Aquino, M. H. O., Dodson, A., Mitchell, C. N., and Wernik, A. W.: Dynamics of high latitude patches and associated small scale irregularities, J. Atmos. Sol.-Terr. Phys., 70, 879-888, doi:10.1016/j.jastp.2007.05.018, 2008.

Doherty, P. H., Delay, S. H., Valladares, C. E., and Klobuchar, J. A.: Ionospheric scintillation effects in the equatorial and auroral regions, in: Proceedings of the 13th International Technical Meeting of the Satellite Division of the Institute of Navigation ION GPS 2000, Salt Lake City, USA, 19-22 September 2000, 662-671, 2000. 
Feldstein, Y. I.: On Morphology and Auroral and Magnetic Disturbances at High Latitudes, Geomagn. Aeron., 3, 183-192, 1963.

Foster, J. C. and Rideout, W.: Mid latitude TEC enhancements during the October 2003 supestorm, Geophys. Res. Lett., 32, L12S04, doi:10.1029/2004GL021719, 2005.

Goodman, J. M.: Space Weather \& Telecommunications, 1st ed., Springer, USA, 2005.

Holzworth, R. H. and Meng, C.-I.: Mathematical representation of the auroral oval, Geophys. Res. Lett., 2, 377-380, 1975.

Hunsucker, R. D. and Hargreaves, J. K.: The High-Latitude Ionosphere and its Effects on Radio Propagation, 1st ed., Cambridge University Press, UK, 2003.

Humphreys, T. E., Psiaki, M. L., Ledvina, B. M., and Kintner, P. M.: Performance of GPS carrier tracking loops during ionospheric scintillations, in: Proceedings of International Ionospheric Effects Symposium, Alexandria, USA, 3-5 May 2005, A010, 2005.

MacDougall, J. W.: Distribution of irregularities in the northern polar region determined from HILAT observations, Radio Sci., 25(2), 115-124, 1990.

Meggs, R. W., Mitchell, C. N., and Honary, F.: GPS scintillation over the European Arctic during the November 2004 storms, GPS Solut., 12, 281-287, doi:10.1007/s10291-0080090-3, 2008

Mitchell, C. N., Alfonsi, L., De Franceschi, G., Lester, M., Romano, V., and Wernik, A. W.: GPS TEC and scintillation measurements from the polar ionosphere during the October 2003 storm, Geophys. Res. Lett., 32, L12S03, doi:10.1029/2004GL021644, 2005.

Moen, J., Gulbrandsen, N., Lorentzen, D. A., and Carlson, H. C.: On the MLT distribution of F region polar cap patches at night, Geophys. Res. Lett., 34, L14113, doi:10.1029/2007GL029632, 2007.

Moen, J., Qiu, X. C., Carlson, H. C., Fujii, R., and McCrea, I. W.: On the diurnal variability in F2-region plasma density above the EISCAT Svalbard radar, Ann. Geophys., 26, 2427-2433, 2008, http://www.ann-geophys.net/26/2427/2008/.
Rino, C. L.: A power law phase screen model for ionospheric scintillation. I-Weak Scatter. II-Strong scatter, Radio Sci., 14, 11351145, 1147-1155, 1979.

Rodrigues, F. S., Aquino, M. H. O., Dodson, A., Moore, T., and Waugh, S.: Statistical analysis of GPS ionospheric scintillation and short-time TEC variations over northern Europe, Journal of the Institute of Navigation, 51(1), 59-75, 2004.

Taylor, J. R.: An introduction to Error Analysis: The Study of Uncertainties in Physical Measurement, 2nd ed., University Science Books, USA, 1997.

Tsunoda, R. T.: High-Latitude F region irregularities: a review and synthesis, Rev.Geophys., 26, 719-760, 1988.

Van Dierendonck, A. J., Klobuchar, J., and Hua, Q.: Ionospheric scintillation monitoring using commercial single frequency C/A code receivers, in: ION GPS-93 Proceedings of the Sixth International Technical Meeting of the Satellite Division of the Institute of Navigation, Salt Lake City, USA, 22-24 September, 13331342, 1993.

Voiculescu, M., Virtanen, I., and Nygrn, T.: The F-region trough: seasonal morphology and relation to interplanetary magnetic field, Ann. Geophys., 24, 173-185, 2006, http://www.ann-geophys.net/24/173/2006/.

Werner, S. and Prolss, G. W.: The position of the ionospheric trough as a function of local time and magnetic activity, Adv. Space Res., 209, 1717-1722, 1997.

Wernik, A. W., Liu, C. H., Franke, S. J., and Gola, M.: Highlatitude irregularity spectra deduced from scintillation measurements, Radio Sci., 25, 883-895, 1990.

Wernik, A. W., Secan, J. A., and Fremouw, E. J.: Ionospheric irregularities and scintillation, Adv. Space Res., 31(4), 971-981, 2003.

Wheelon, A. D.: Electromagnetic Scintillation: II. Weak Scattering, 1st ed., Cambridge University Press, UK, 2001.

Wielgosz, P., Baran, L. W., Shagimuratov, I. I., and Aleshnikova, M. V.: Latitudinal variations of TEC over Europe obtained from GPSobservations, Ann. Geophys., 22, 405-415, 2004, http://www.ann-geophys.net/22/405/2004/. 